\title{
The Creation of an Experiential Engineering Library
}

\author{
James T. McLeskey, Jr., John E. Speich, \\ Judy S. Richardson, and Mohamed Gad-el-Hak \\ Virginia Commonwealth University, Richmond, VA 23284, USA
}

In preparation for solving twenty-first century problems, today's engineering students need twenty-first century examples. These students also express a need for hands-on activities to help them understand the theories they learn in class. Satisfying these criteria while ensuring mastery of the fundamentals is becoming an increasingly greater challenge given the time constraints of the typical mechanical engineering curriculum. In order to meet this challenge, the VCU Mechanical Engineering Department has begun development of an NSF-sponsored "Experiential Engineering Library" that will provide an easily accessible environment for hands-on learning experiences beyond the traditional Mechanical Engineering curriculum. The library will foster critical thinking by encouraging students to apply fundamental mechanical engineering principles to interdisciplinary research in emerging fields such as microelectromechanical systems (MEMS), bioengineering, and nanotechnology. The present article describes the library concept, elaborates on its contents, and describes its impact on student interest and performance in a pilot course: Energy Conversion Systems.

\section{Concept}

The envisioned Experiential Engineering Library will be analogous to a traditional library. It will ultimately contain a large number of experiments and computer simulations either "on reserve" or available to be "checked out" by the students. At the instructor's discretion, hands-on problems can be assigned as a complement to, or in lieu of, paper and pencil homework. The learning modules can also be used independently by students seeking to improve their understanding through manipulation and visualization. Additional activities will provide enrichment opportunities for both undergraduate and visiting secondary school students. The flexibility and integration of the experiments in the library make it superior to laboratories used in traditional engineering courses.

Many of the examples currently used in Engineering curricula seem better suited to the "Greatest Generation" than to the students in school today. While some of these examples are still educationally sound, twenty-first century students need twenty-first century examples. Our experiments are intended to promote learning through guided inquiry. There is a constant battle in educational circles between traditional explicit instruction where students are told what they need to know and then expected to know it and discovery learning where students are given a few parameters and then given the chance to "play" and figure out the way things work. The former seems more expedient and most engineering faculty seem more comfortable with this method. It is relatively easy to grade objectively (the answer is either right or wrong) and is well-suited for preparing students for standardized tests. The latter reflects constructivist 
learning theory ${ }^{1,2}$, which has been shown to increase - as well as engage-learners more effectively than traditional lecture instruction. Components of a constructivist environment include: shared knowledge; authentic, real world tasks; scaffolding; cognitive apprenticeship; learner control; and non-linear instruction ${ }^{3}$. It therefore encourages collaborative learning and team-building. The intention of the subject library is for the students to perform guided experiments and discover the answers to their questions. More details about the library concept are provided in another paper ${ }^{4}$.

\section{Content}

The Experiential Engineering Library collections will allow students to study problems of interest in emerging fields that come from a number of sources including: faculty research, senior capstone design course projects, commercially developed educational tools, and donations from industrial partners. Our Mechanical Engineering faculty includes experts in smart materials and nanomaterials, surgical and rehabilitation robotics, traditional and alternative power generation, acoustics and vibration, flow control and MEMS. These experts will provide examples from their research that excite the students while teaching fundamental principles. For example, students can build nanotechnology-based solar cells from simple materials or measure the range of motion of their hands using a robotic device for hand rehabilitation therapy. In the past, senior design course students have built an adaptive video game controller for children with disabilities, a hang glider simulator complete with support sling, and a fully-functional continuously variable transmission. Teams of senior students will be encouraged to develop projects for the library that demonstrate important engineering concepts to mechanical engineering students at all levels.

In order for the library to be used by the students, it must be in a convenient location and open for a sufficient number of hours. In its early stages, the library is being located in two laboratories belonging to the first two authors. These laboratories are both located in the School of Engineering building at VCU where nearly all engineering classes are taught. The library will be kept open approximately 20 hours per week by undergraduate librarians. These librarians will be trained to monitor and maintain the experiments and assist students that visit the library. Specific instructions will be included with each experiment and also posted on the web. These instructions will be written in a way that will encourage self-guided learning.

The courses earmarked for inclusion in the first stage of the library development are Thermodynamics, Mechanics of Deformables, Dynamics, and Energy Conversion Systems. The experiments will be incorporated into these courses in a number of ways. While traditional inclass demonstrations can be instructive, the intent of the library is to involve the students more directly. Instead of restricting activities to pencil and paper homework, assignments will be made that require use of the library. Certainly traditional homework problems will continue to be assigned, but some of these will be replaced or supplemented with experiments in the library.

Another area where the library will be useful is in the development of "reserve" materials. Much like the reserve reading materials that are often included on a syllabus, these extracurricular assignments would give all students a way to enhance their understanding, especially those whose learning styles include kinesthetic and manipulation techniques. We recognize that the 
traditional reserve readings are under-utilized. It is our hope and belief that hands-on experiments designed around state-of-the-art research (solar cells, robotics, MEMS, smart materials, etc.) will stimulate more interaction and interest in learning among students.

Other types of assignments may be developed as well. Team projects can be developed for both users and suppliers of the library. For users, theoretical calculations done in class can be checked in the lab. For example, students can derive the kinematic equations for a five-bar linkage and then verify the equations using a rehabilitation robot with a five-bar linkage configuration. Criteria can be added to senior design requirements that encourage the teams to design projects that can be used in the library following completion. During the Fall 2003 semester, a group of four seniors began developing a library module based on faculty research that will use surgical instruments implemented with force sensors to illustrate the concepts of stress and strain.

Impact

The Experiential Engineering Library was first piloted in the curriculum during the fall 2003 semester in a senior technical elective course: Energy Conversion Systems. Two different modules were utilized and the results are evaluated below. In the first module, the students built a simple Stirling engine. This module was assigned as a homework assignment with no prior introduction in class. In the second module, the students built and tested a nanocrystalline solar cell. In this case, photovoltaics had been discussed during the lecture prior to the assignment. While both experiments are available commercially in kit form, they nonetheless represent the state-of-the-art in Energy Conversion Systems and both are the subject of ongoing research ${ }^{5,6}$. An evaluation of the impact of these modules on student learning was conducted using pre and post self-assessments and the results of these self-tests are presented. In addition, focus group interviews were conducted to gather qualitative expressions of student satisfaction and perceptions of learning.

\section{Stirling Engine}

The Stirling engine module (see Fig. 1) was based on a model available in kit form from Fisher Scientific ${ }^{7}$. The model uses a test tube and marbles as the transfer cylinder and piston and a rubber stopper and balloon as the power cylinder and piston. The module was assigned in lieu of one homework problem with no prior introduction in class. All 19 students in the Energy Conversion Systems course completed the Stirling engine library module over the course of one week. Each student worked independently. The students were given a nine question pre-test to assess their knowledge of Stirling engines. They were also asked to rate their existing knowledge of Stirling engines on a scale from one (no knowledge) to ten (expert). After completing the experiment, they were given a post-test. The post-test included the same nine questions and self-rating. In addition, the students were asked whether the lab was helpful in increasing their knowledge of Stirling engines and whether or not the lab peaked their interest in Stirling engines. Finally, the students were given the opportunity to make written comments. 


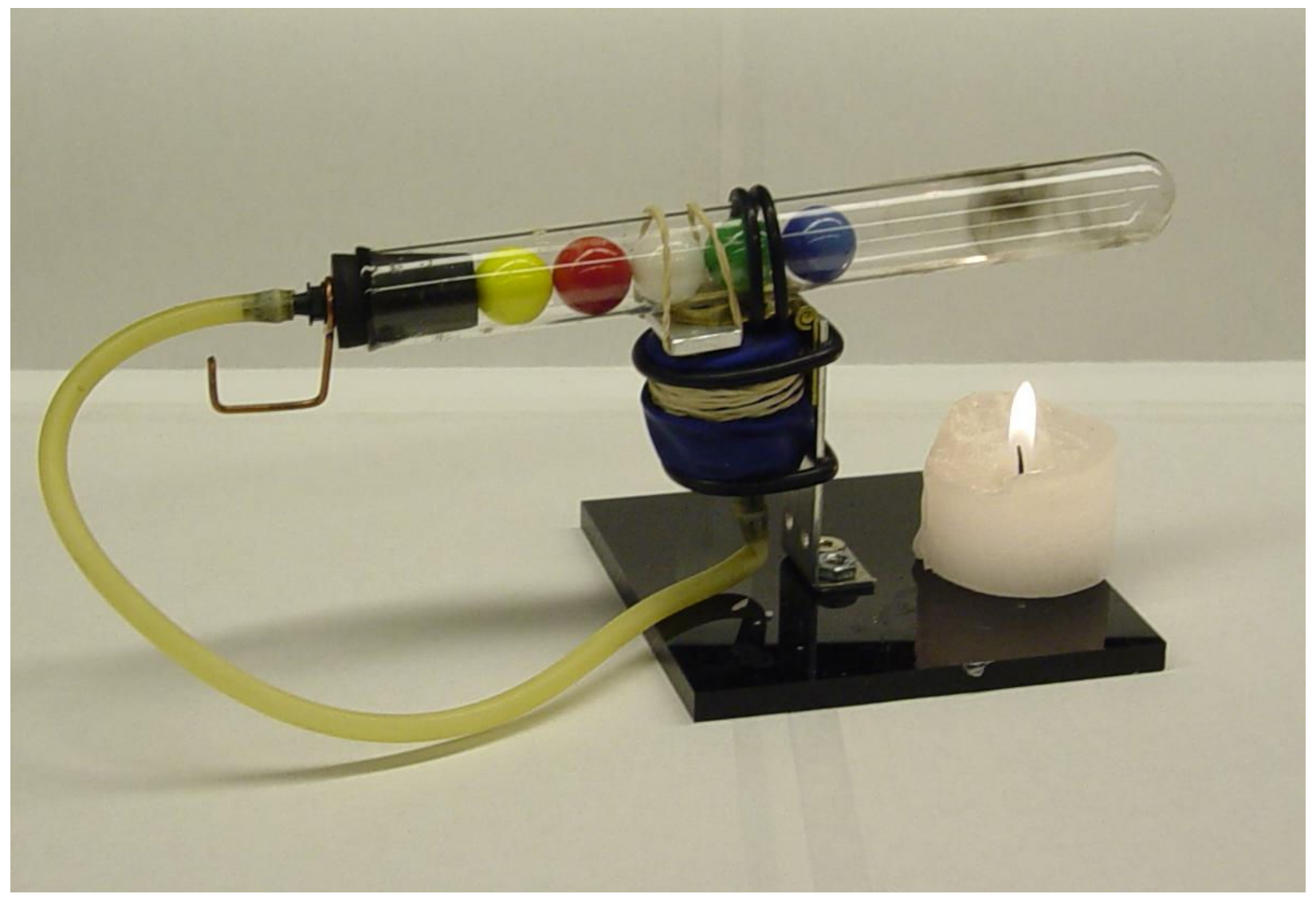

Fig. 1 Stirling engine model[ref] used in the Experiential Engineering Library

Each student's scores on the pre-test and post-test are shown in Figure 2. The average percentage of correct responses was $69.6 \%$ on the pre-test and $94.1 \%$ on the post-test, with standard deviations of $13.3 \%$ and $9.3 \%$ respectively. The averages are presented graphically in Figure 3 with error bars that show \pm 1 standard deviation. Clearly, reading the instructions and completing the module improved the students' abilities to answer the questions correctly.

As stated above, each student rated his/her existing knowledge of Stirling engines on a scale from one (no knowledge) to ten (expert) before and after completing the library module. The self-assessment scores are shown in Fig. 4. The average rating was 2.8 on the pre-test and 7.1 on the post-test, with standard deviations of 1.6 and 1.8 respectively. The averages are presented graphically in Fig. 5 with error bars that show \pm 1 standard deviation. When asked whether or not the lab was helpful in increasing their understanding of Stirling Engines, seventeen of nineteen (89\%) answered affirmatively. The students clearly believed that they had increased their expertise. It should be noted however, that one of the two students who rated their knowledge as 10 on the self-evaluation did not answer $100 \%$ of the post-test questions correctly, but the student who rated his/her post-lab knowledge as 2 answered $100 \%$ of the questions correctly. Students also found the lab enjoyable and intriguing. Fifteen of nineteen (79\%) said the lab peaked their interest in Stirling Engines. This is also supported by the student comments listed in Table 1. 


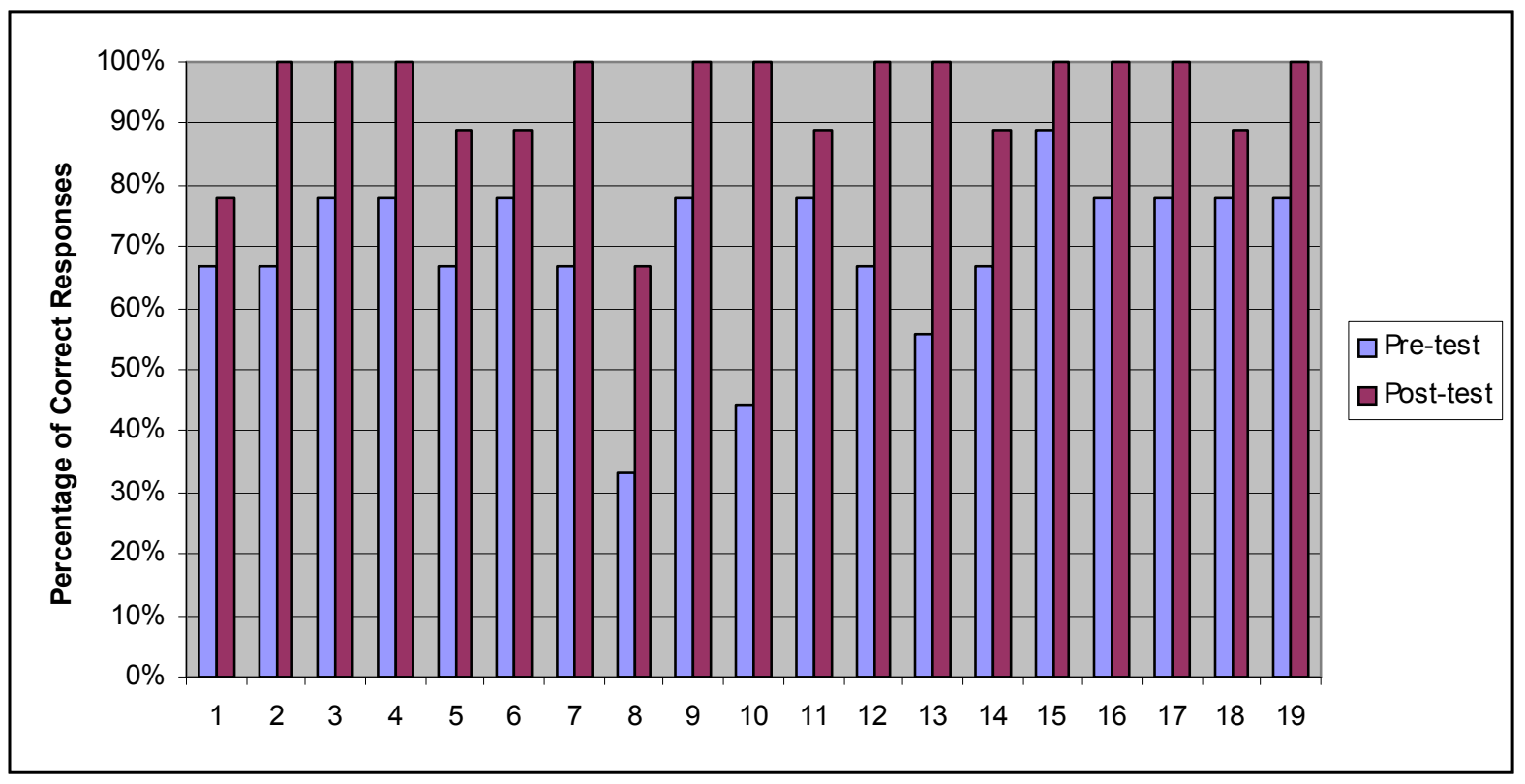

Fig. 2. Percentage of correct responses for the Stirling engine pre-test and post-test.

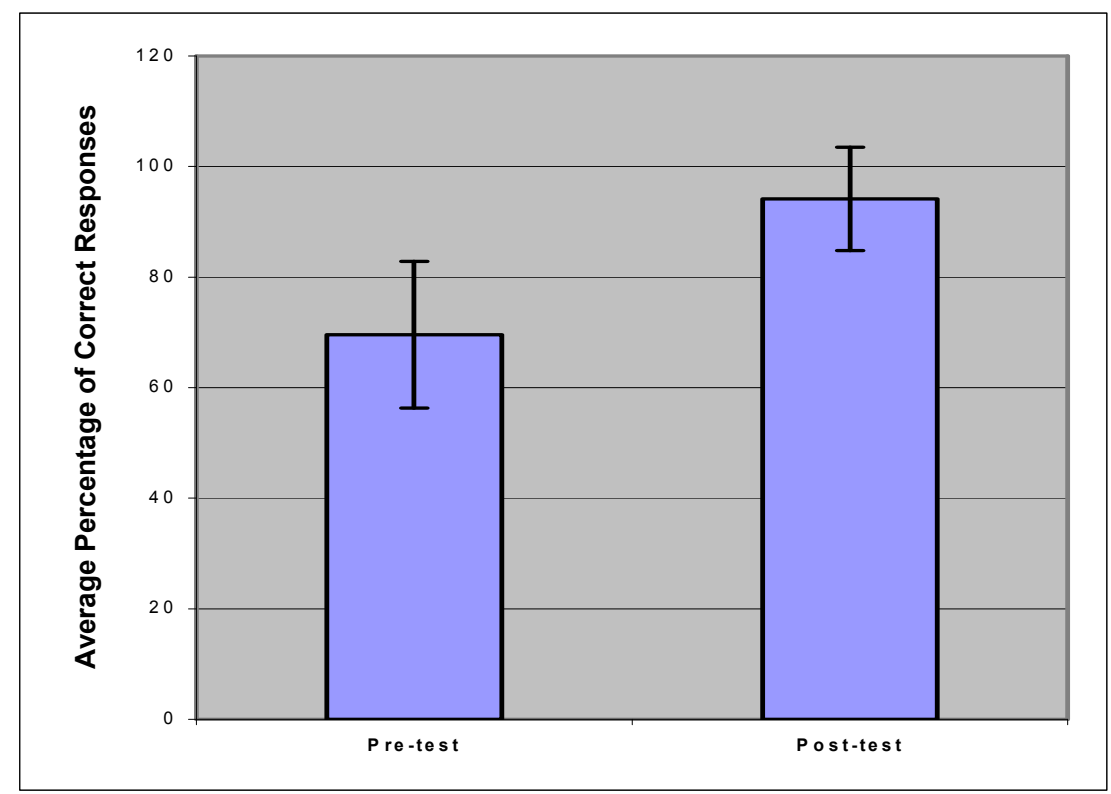

Fig. 3 Average percentage of correct responses for the Stirling engine pre-test and post-test. The error bars show \pm 1 standard deviation. 


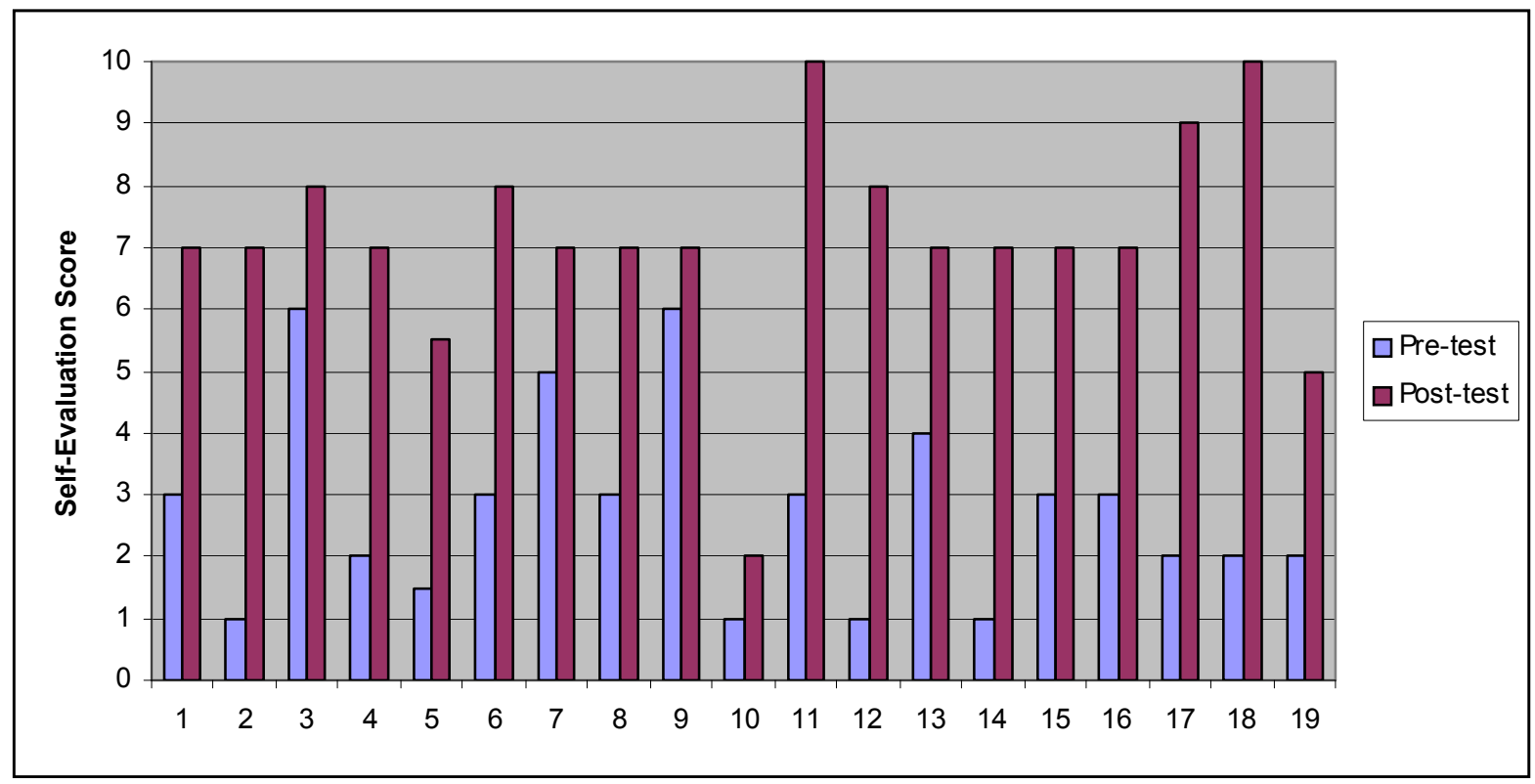

Fig. 4. Self-evaluation scores in which students rated their knowledge of Stirling engines on a scale from 1 (no knowledge) to 10 (expert) before and after completion of the Stirling engine library module.

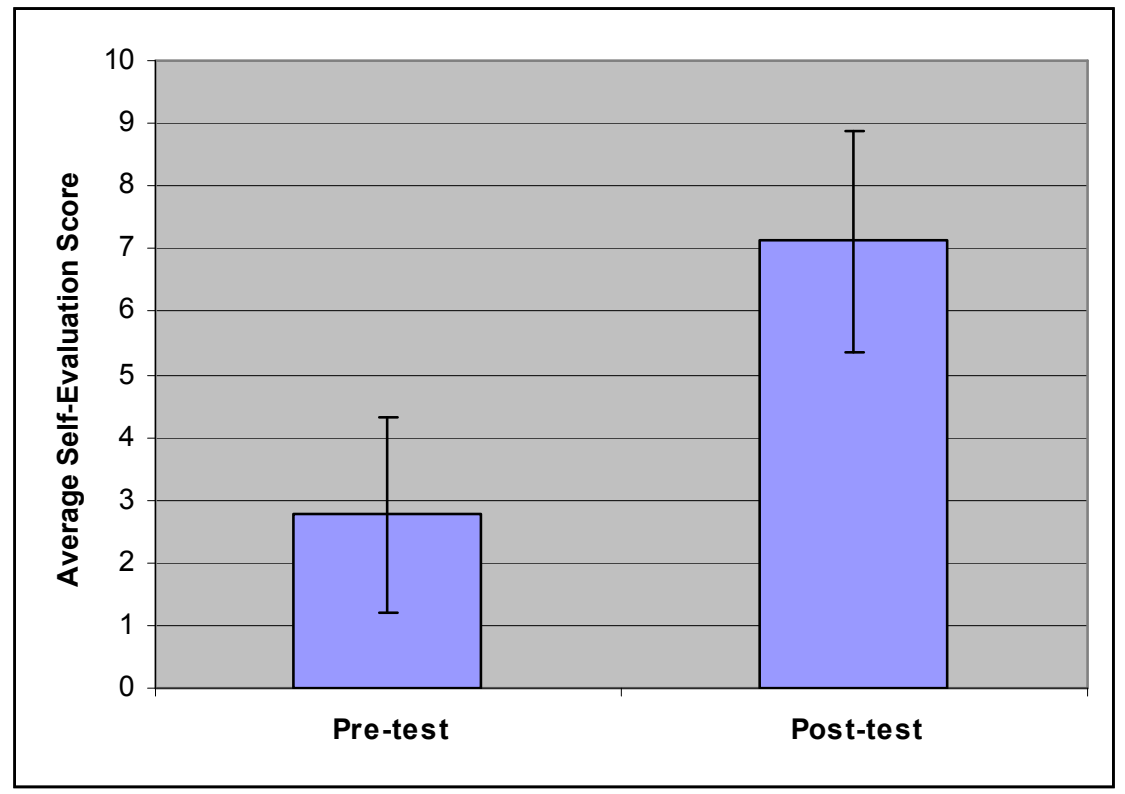

Fig, 5. Average self-evaluation scores in which students rated their knowledge of Stirling engines on a scale from 1 (no knowledge) to 10 (expert) before and after completion of the Stirling engine library module. The error bars show \pm 1 standard deviation. 
Table 1 Student's written comments about the Stirling engine module

\begin{tabular}{|l|}
\hline Great Interactive Learning Experience \\
\hline Lab helped me understand how the Stirling Engine worked \\
\hline I am going to build one at home \\
\hline Cool lab. Stirling Eng's are very interesting \\
\hline More detail diagrams w/ instructions would help \\
\hline Fine tuning the engine to work properly is difficult \\
\hline I kinda got it to work \\
\hline I have never seen a Stirling engine before and never thought that it was so simple \\
\hline Fun lab. Finiky Engine \\
\hline
\end{tabular}

Nanocrystalline solar cell

The Nanocrystalline solar cell module was based on a model available in kit form from the Institute for Chemical Education at the University of Wisconsin ${ }^{8}$. In this module the students can build their own solar cells (Fig. 5) in a lab using simple materials including titanium dioxide and blackberry juice. The resulting solar cells can then be tested for important values including voltage and current (and thus power). For a known solar flux, the energy conversion efficiency of the solar cell can be calculated.

The promise of "free energy" offered by photovoltaic solar energy conversion is very enticing to students. This experiment offers them the opportunity to build a nano-crystalline solar cell while learning about the limits imposed by the first and second laws of thermodynamics. It also illustrates the interrelationships between the various disciplines of science and engineering and could be used in teaching Thermodynamics, Heat Transfer, and Energy Conversion Systems. This gives the students the opportunity to revisit the same experiment as they learn new concepts, thus helping to build continuity.

The module was assigned in lieu of one homework problem. Unlike the Stirling engine module, the students had some prior knowledge because the solar cell module was assigned at the end of a unit on solar energy and photovoltaics. Prior to attempting the experiment, the students were given a five (5) question anticipation guide to test their knowledge of Nanocrystalline solar cells. The student was required to answer each question either "Agree" or "Disagree" and give a rationale for each answer. "Anticipation guides, sometimes called reaction or prediction guides, prepare readers by asking them to react to a series of statements that are related to the content of the material. In reacting to these statements, students anticipate, or predict, what the content will be. Once students have committed to the statements, a purpose for reading has been created. Students' curiosity about their predictions can help maintain a purpose for thoughtful reading." 9 . After completing the experiment, they were given the same anticipation guide as a post-test to see if they had improved their ability to answer the questions. At the end, the students were given the opportunity to make written comments. Whereas the Stirling engine model focused building and then adjusting the engine to make it work properly, the solar cell module required building the solar cell and then testing its properties by measuring and plotting current and voltage. 


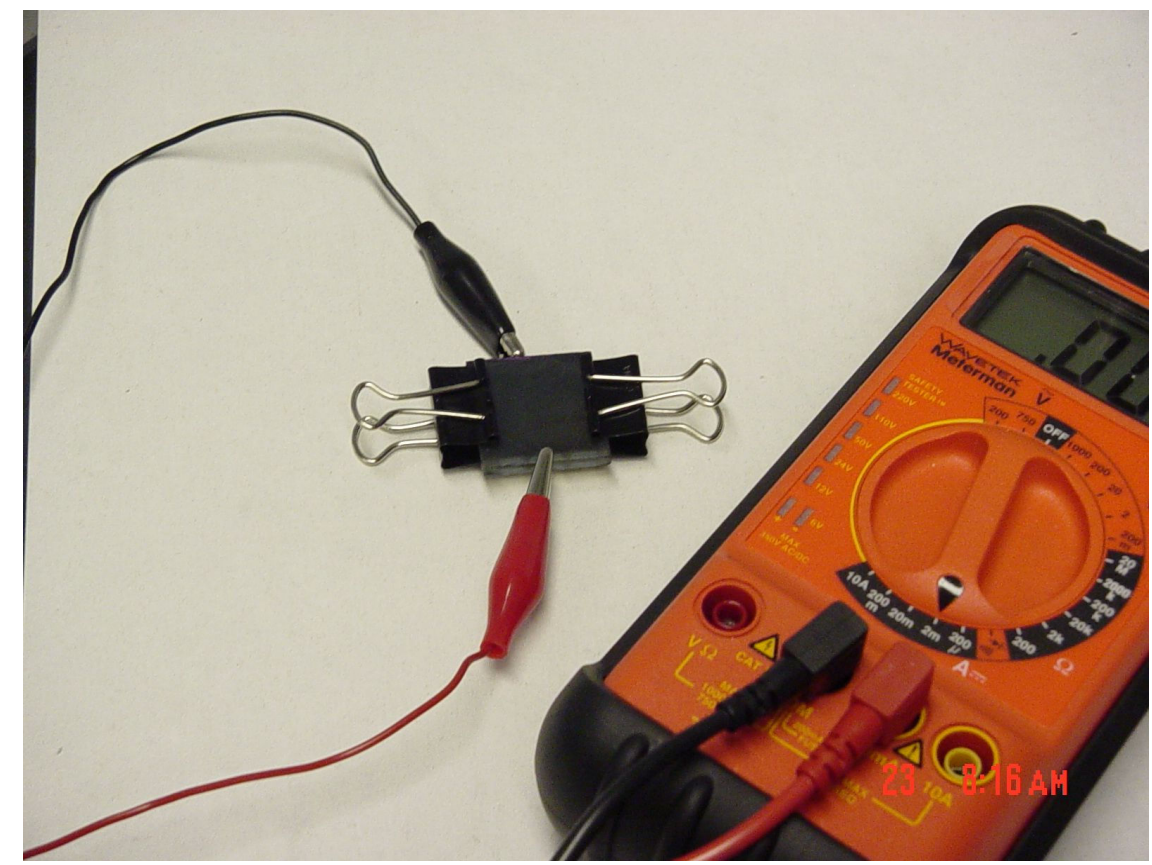

Fig. 6 Nanocrystalline Solar Cell used in the Experiential Engineering Library

The solar cell library module was completed by all 19 students in the Energy Conversion Systems course; however only 16 students submitted both the pre-test and post-test. Each student's scores on the pre-test and post-test are shown in Fig. 7. The average percentage of correct responses was $70 \%$ on the pre-test and $80 \%$ on the post-test, with a standard deviation of $14 \%$ on both tests. The averages are presented graphically in Fig. 8 with error bars that show \pm 1 standard deviation.

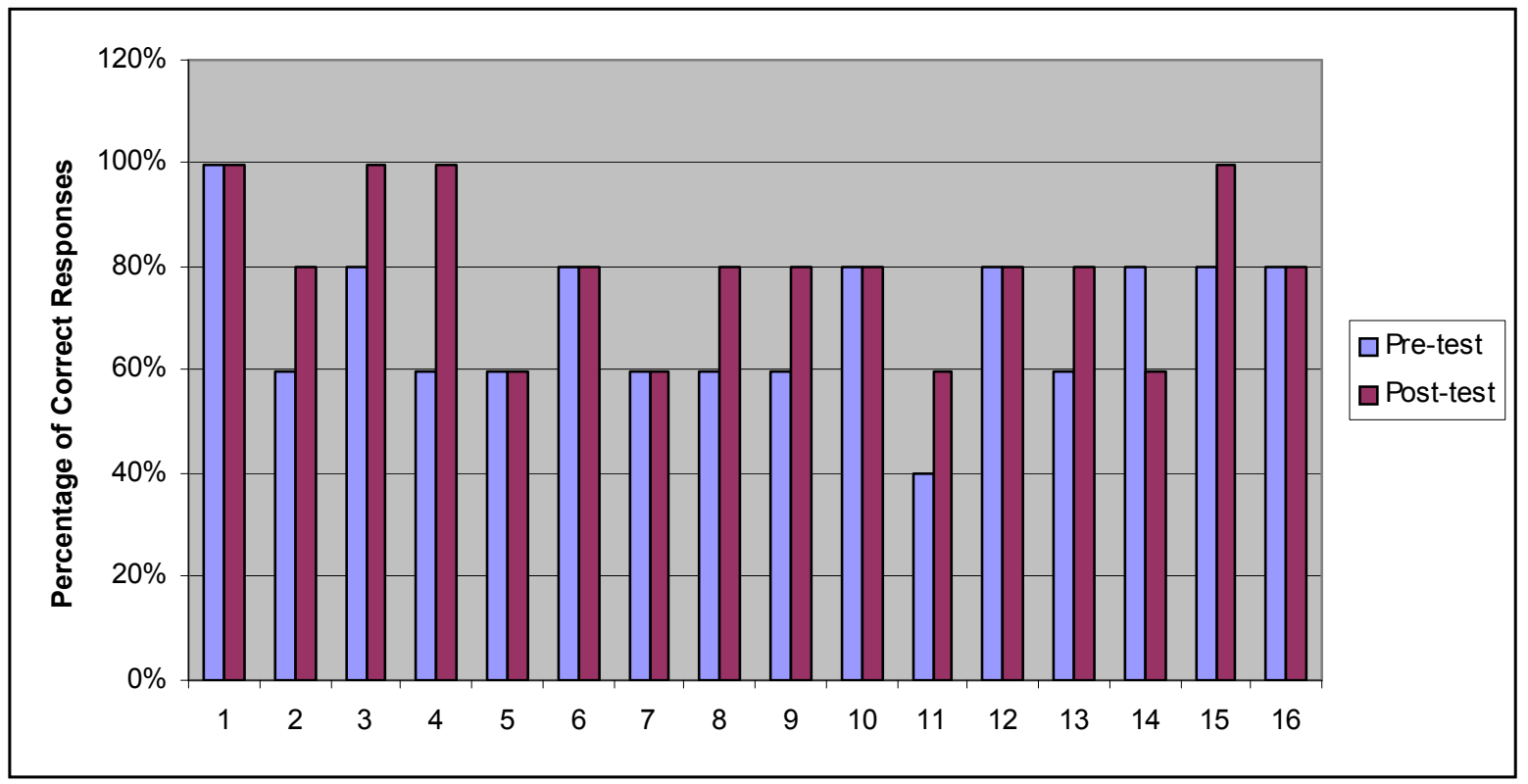

Fig. 7 Percentage of correct responses for the solar cell module pre-test and post-test. 


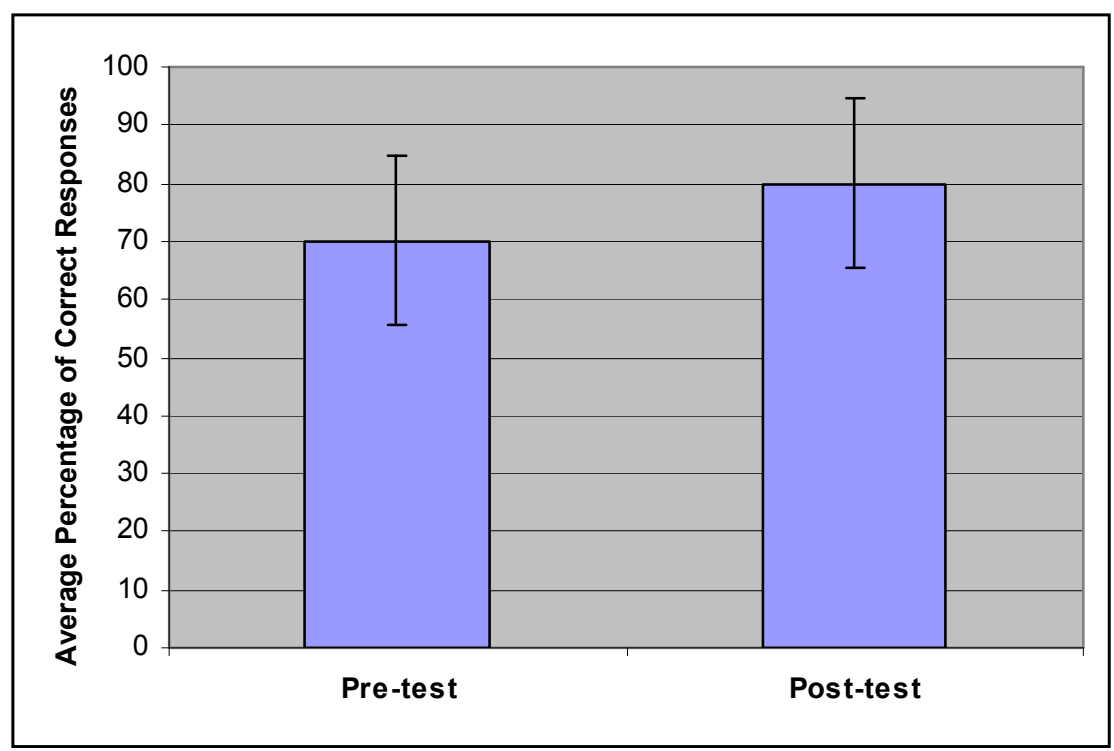

Fig. 8 Average percentage of correct responses for the solar cell module pre-test and post-test. The error bars show \pm 1 standard deviation.

While there is some improvement in the students' performance on the evaluation after completing the module, the results are not as dramatic as with the Stirling engine module. In part, this is probably due to the fact that the solar cell module was done after the topic was discussed in class. In addition, the student comments given in Table 2 show that the students had some difficulty in getting the expected results. Although the module instructions followed those supplied with the kit. And while all of the students got some electrical output from the solar cell, many experienced difficulty in getting the cell to reach its design specifications. This indicates that the details of the fabrication and testing procedures need to be adjusted.

Table 2 Student's written comments about the nanocrystalline solar cell module

\begin{tabular}{|l|}
\hline Circuit didn't work properly \\
\hline Had a lot of problems with lab \\
\hline Interesting lab to actually see how simple the cells are and how they work \\
\hline We didn't get a very good graph and didn't understand how it got to $0.2 \mathrm{~V}$ \\
\hline My solar cell is not powerful. \\
\hline I got part of the I-V curve that looks like ideal curve. \\
\hline I think that my solar cell has not enough berry juice or I put too much water in the juice \\
\hline Our output voltage/current was not very good - maybe something was wrong with the cell \\
\hline This cell was hard to make properly. \\
\hline
\end{tabular}

Focus group interview

Following the conclusion of the semester, Dr. Richardson from the VCU School of Education conducted a focus group interview with several students in the Energy Conversion Systems class. The students had not met Dr. Richardson prior to the interview and the course instructor (Dr. McLeskey) was not present. Because an education professor conducted the focus group and had 
had no contact with these students previously, her presence was considered to be nonthreatening. Four of the nineteen members of the class attended the interview.

The focus group met for 70 minutes. The session was audio taped and video taped for transcription purposes. To maintain student confidentiality, a student assistant transcribed the audiotapes. Videotapes were used only to correctly assign comments to the correct student when it was impossible to use the audiotape for this purpose. This occurred when comments were extremely brief or when students spoke simultaneously. No engineering faculty member listened to or watched any tapes. Their involvement in the analysis process took place only after the transcriptions were complete. The tapes were erased following the final audit. The transcript of the focus group was analyzed using qualitative analysis. The transcript underwent a line-by-line content analysis ${ }^{10}$. The data corpus was repeatedly reviewed to test the validity of the assertions 11.

The focus group was led via a series of prompts that were designed to encourage thoughtful comment about student experiences with the Experiential Library. These prompts probed for: ease of use, increased class performance, deepened understanding of content and concepts, the "hands-on" aspect (constructivism), interest, and overall impressions of the Experiential Library. Since the final coding is not yet complete, the comments presented here are organized around the prompts and direct quotations support the findings.

According to the student comments, the Experiential Library was "pretty easy" to access and use. Students felt that they could stop by "whenever it was convenient for us." Furthermore, they often experimented much longer than the actual task required: "You could sit there and play with it after you built it." (Referring to the Stirling Engine).

While students commented that the Experiential Library helped them to perform better in class, they valued more so that the lab would help them remember and apply information in their future careers. "If somebody were to mention this 10 years later, I think I would remember this;" "It would help us down the road explaining it to somebody in a simpler way."

The students were very impressed with their deepened sense of content and concepts after having completed the Experiential Library tasks. "Now I see how it works. Sitting in lecture, you know how it works on paper and from the book but actually doing it you can see what goes on;" "When you actually see it, you understand it;" "Putting things in context adds a lot more gravity to it."

The students were very excited to have an opportunity to "do" as well as to listen and read. They appreciated seeing and manipulating so that they could really understand how the theory works. That was why they wanted to see if they could keep the Stirling Engine going past the task assigned. "I liked that Dr. McLeskey is going for this hands-on stuff:" "I'm the kind of person that I have to see and feel something to understand it."

The students expressed much enthusiasm for the activities. It made the subject more interesting for them, especially because they were planning to be mechanical engineers and these experiments helped them to grasp electrical engineering better. They volunteered that the 
Experiential Library provided excellent opportunities for application; in fact, they suggested that the pre and post tests should better reflect the applicative nature of the tasks and not dwell on the facts so much as the application of the facts.

Overall, these students were very impressed with the Experiential Library. Their appreciation for the constructivist nature of the Experiential Library was apparent. As one student said, "You develop a relationship with the idea." The focus group students are some of the students of the twenty-first century and their comments reflect their needs for and appreciation of the Experiential Library as a way of meeting those needs.

Conclusions and future work

When well-designed modules were developed, the Experiential Engineering Library has shown to increase student interest and improve student performance. The library can be used successfully to either introduce a topic or re-enforce material already. Student scores increase markedly when topics are taught using the library. Students constantly extol the virtues of learning via manipulation.

The library is still in the pilot stage and during the spring semester a number of additions will be made. The Stirling engine and solar cell experiments will be incorporated into a Thermodynamics class. Additional library modules involving rehabilitation robotics and forcesensing surgical instruments are being created from faculty research and will be utilized in the appropriate classes. Classes may be split with some students using the library and others simply working pencil and paper problems to determine if there is a significant difference in performance. The pre and post test content and procedures will be altered to reflect the suggestions of the focus group students. As time goes by, the modules can be improved. For example, the Stirling engine could be instrumented to measure pressure and temperature using a data acquisition system. The additional experience gained would have to be balanced against the loss of simplicity.

\section{Acknowledgments}

The authors would like to thank the National Science Foundation for its support of this project under the Grants for the Department-Level Reform of Undergraduate Engineering Education Program, NSF Grant \# 0342865.

\section{Bibliography}

${ }^{1}$ Vygotsky, L., Thought and Language. 1962, Cambridge, MA: MIT Press.

${ }^{2}$ Vygotsky, L., Interaction between learning and development, in Mind in Society: The develoment of Higher Psychological Process, M. Cole, et al., Editors. 1978, Havard University Press: Cambridge, MA. p. 79-91.

${ }^{3}$ Norman, S., EPSS: A constructivist learning environment, http://scholar.coe.uwf.edu/students/snorman/webpages/paperpresentation/sld001.htm, April 21, 2002.

${ }^{4}$ Speich, J., et al., The Experiential Engineering Library. International Journal of Engineering Education, In review.

${ }^{5}$ de Boer, P.C.T., Maximum attainable performance of stirling engines and refrigrerators. Journal of Heat Transfer, 2003. 125(5): p. 911-915. 
${ }^{6}$ Gratzel, M., Photoelectrochemical cells. Nature, 2001. 414: p. 338-344.

${ }^{7}$ Fisher Scientific, Stirling Engine Model, www.fishersci.com, December 18, 2003.

${ }^{8}$ Smestad, G., Nanocrystalline Solar Cell Kit: Recreating Photosynthesis, ed. A. Huseth and K. Shanks. 1998, Madison, WI: The Institute for Chemical Education.

${ }^{9}$ Richardson, J.S. and R.F. Morgan, Reading to learn in the content areas. 2003, Belmont, CA: Wadsworth.

${ }^{10}$ Bogdan, R.C. and S.K. Biklen, Qualitative research for education. 1982, Boston: Allyn and Bacon.

${ }^{11}$ Erickson, F., Qualitative methods in research on teaching, in Handbook of research on teaching, M. Wittrock, Editor. 1986, Macmillan: New York. p. 119-161.

\section{Biography}

JAMES MCLESKEY is an Assistant Professor of Mechanical Engineering at Virginia Commonwealth University. He earned his B.S. in Physics from The College of William and Mary, his M.S. in Mechanical Engineering from the University of Illinois at Urbana-Champaign, and his Ph.D. in Mechanical Engineering from the University of Virginia. Dr. McLeskey is certified by the State of Virginia to teach high school Physics and Chemistry.

JOHN SPEICH is an Assistant Professor of Mechanical Engineering at Virginia Commonwealth University. He earned his B.S. in Mechanical Engineering from Tennessee Technological University and his M.S. and Ph.D. in Mechanical Engineering from Vanderbilt University.

JUDY RICHARDSON is a Professor in the School of Education at Virginia Commonwealth University. She earned her B.A. degree in English from the University of North Carolina, Greensboro and her M.Ed. and Ph.D. degrees in Education from the University of North Carolina, Chapel Hill.

MOHAMED GAD-EL-HAK is the Caudill Eminent Professor and Chair of Mechanical Engineering at Virginia Commonwealth University. He earned his B.Sc. in Mechanical Engineering from Ain Shams University and his Ph.D. in Fluid Mechanics from Johns Hopkins University. Dr. Gad-el-Hak is a fellow of the American Academy of Mechanics, the American Physical Society, and the American Society of Mechanical Engineers. 